\title{
A Stakeholder Approach to Risk Management
}

\begin{abstract}
In crisis management, risk management has been conceived mainly as a proactive pre-crisis management effort where it is deployed for crisis prevention and preparedness efforts. This chapter argues that risk management extends into the entire crisis management continuum, as crises ignite new types of risks with their associated stakeholders. Organizations should continually identify, manage and communicate risks to key stakeholders during the different phases of crisis management. A stakeholder orientation demands that organizations seek and involve risk stakeholders in the risk management process. The level of involvement will depend on both the identified risks and how stakeholders are expected to be affected by the proposed solutions and decisionmaking processes.
\end{abstract}

Keywords Risk management $\bullet$ Risk communication $\bullet$ Media framing

\section{INTRODUCTION}

Risk refers to the probability that an undesirable event, situation or condition will occur. For Ulrike Beck, "risks are always future events that may occur, that threaten us" (Beck, 2009, p. 9). There are many types of risks in an organization's environment and these change constantly and so do the risk stakeholders. Risks can come from various sources in the environment, including uncertainty, human error, natural causes and 
disasters. Risk management involves processes for identification, analysis and evaluation of risks. In crisis management, risk management has been conceived mainly as a proactive pre-crisis management effort where it is deployed for crisis prevention and preparedness efforts (Coombs, 2015). In this chapter, I argue that risk management extends into the entire crisis management continuum. Crises ignite new types of risks with their associated stakeholders. Organizations should continually identify, manage and communicate risks to key stakeholders during the different phases of crisis management. A stakeholder orientation demands that organizations seek and involve risk stakeholders in the risk management process. The level of involvement will depend on both the identified risks and how stakeholders are expected to be affected by the proposed solutions and decision-making processes.

\section{Overview of the Risk Management Process}

Numerous procedures exist in relation to risk management processes, ranging from three-step processes to as many as seven-step processes. Kallman and Maric (2004) propose a five-step model for risk management (with 15 stages). The following model illustrates the key components of the risk management process (Fig. 4.1).

The degree of stakeholder engagement in each of these phases depends on the nature of the identified risks and how the proposed solutions and decision processes are likely to impact on the stakeholders.

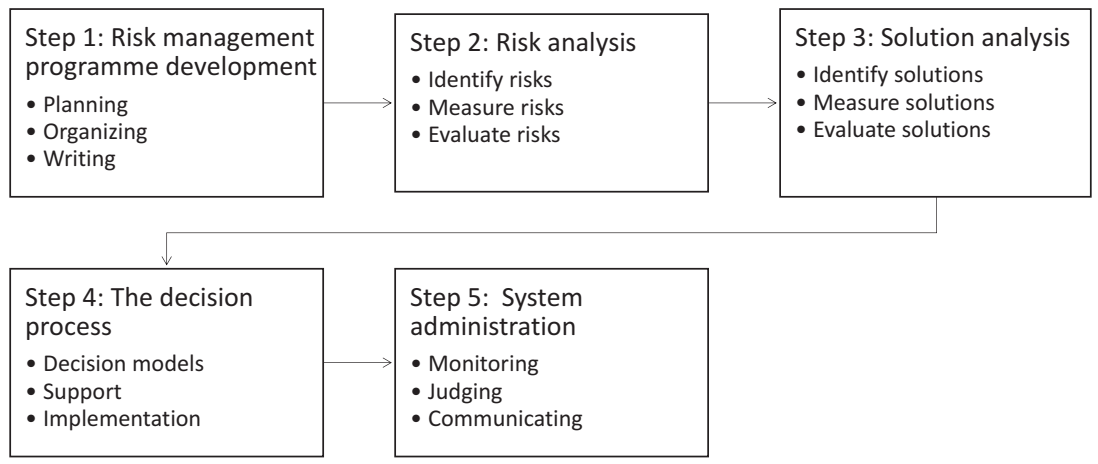

Fig. 4.1 Five-stage model for risk management 


\section{ENGAGING RisK STAKeHOLDERS}

Behind every risk are individuals, groups or social actors who are (or who perceive themselves to be) affected by a risk (or decisions, strategies and/ or processes in its management). These stakeholders are dynamic and likely to change during the course of the process. Some are constant, while others come and go, and others may join in at different stages of the process. Therefore, it is important for the organization to engage with these stakeholders. Stakeholder participation in the risk management process is becoming increasingly recognized as a means of producing decisions that are responsive to the varying interests and values (Jardine, 2008). The benefits of engaging stakeholders are many and include a better understanding of the risk, building trust and credibility as stakeholders feel involved in decision-making and actions affecting their future, stakeholders feel that their interests are taken seriously by the organization. Engagement generates mutual understanding and sharing of responsibility if things go wrong. It also allows risk stakeholders to express their opinion on the risk and the actions taken by the organization to address it, as well as its potential outcome. Engaging with a variety of stakeholders provides a platform for different voices to be heard. Different risk stakeholders can be consulted at different stages of the risk management process.

In order to engage appropriately with the stakeholders, the organization needs to know who they are, and how they are involved. The following simple steps can be undertaken to understand, map and plan risk stakeholder engagement.

- Identify and analyse risk stakeholders

- Prioritize risk stakeholders

- Plan risk stakeholder management

- Risk stakeholder engagement

\section{STAKeHOLDER Risk COMMUNiCATION}

Risk communication is an important process for soliciting opinions and disseminating information about the risk to stakeholders. It is an integral aspect of a risk management process, which requires different forms of communication and information activities at different stages and levels of the process directed at specific target risk stakeholder groups. Risk communication can be defined as "any public or private communication that 
informs individuals about the existence, nature, severity, or acceptability of risks" (Plough \& Krimsky, 1987, p. 6). The perspective on stakeholders (audiences) is embedded in definitions of risk communication, be they source- or sender-oriented definitions focusing on conveying or transmitting information, from the risk assessors to the stakeholders, or interactive process definitions focusing on the exchange of scientific information between interested parties (Covello, Winterfeldt, \& Slovic, 1987; Infanti et al., 2013). Exchange of information is understood as an attempt to define risk communication as an audience-oriented activity in which the source customizes scientific information to the questions and needs of target groups in the public (Gutteling \& Wiegman, 1996). Risk communication can be understood as a dynamic and interactive process involving exchanges between different stakeholders. It can either be a planned or unplanned communication with stakeholders, or what has been referred to as 'interested parties', about the nature, possible consequence and management of risks.

Risk communication is thus a strategic management activity that involves the ability to communicate effectively the nature and magnitude of risks to the internal and external stakeholders. Crucial to risk management is not only recognizing the problem, but also communicating the risks to the key stakeholders. Risk management processes would be futile if internal stakeholders were not included in the processes. The same applies to the sharing of risk information in interorganization networks, especially crisis management organizations like the police, defence and security. In analysing risks and solutions, risk managers should also consider how the chosen solutions would affect stakeholders. The risk decision processes thus involve different ways of engaging and accommodating internal and external stakeholder interests. Communication skills for persuading different stakeholders, convincing conflicting stakeholder interests, reaching compromises and satisfaction of the key stakeholders are fundamental to effective risk communication. Risk management solutions are likely to fail if stakeholder groups feel that they have not been properly informed.

In the field of crisis management, risk communication has been applied for proactive control (prevention) or strategy formulation (crisis preparedness). Prevention strategies include, for example, public safety communications and warnings to the public. It can be warnings to inform the public about hazards, dangers and risks in their environment. Such warnings include instructional communication as to how to deal with or avoid the 
hazards. The goal of such communication is to avoid or minimize the consequences of the hazards. It seeks to eliminate situations or events that, if they occur, can lead to injury or loss of property. The Institute of Medicine (1997) identified three purposes of risk communication:

1. Advocacy - to influence stakeholders to change their behaviour or to adopt particular practices such as using seat belts.

2. Education - to give people enough information so that they can make their own decisions effectively.

3. Promotion of decision-making partnership — to involve people actively in risk management options.

Covello et al. (1987) distinguish four areas in which risk communication is applied: (1) informing and education-where people are informed and educated about the risks; (2) stimulating behavioural change and taking protective measures, which tries to encourage risk reduction behaviour by influencing the perception of the audience; (3) disaster warnings and emergency information, which provides instructions and guidance during disasters and emergencies; and (4) exchange of information and a common approach to risk issues, which involves the public in risk management processes. Different types of risk will require different forms of risk communication.

\section{Persuasive Risk Communication}

Persuasive risk communication is often used when the intention of the communicator is to change behaviour. It entails persuasive efforts by risk communicators to change the behaviours, attitudes and opinions of specific groups or stakeholders regarding a risk issue. Miller (1980) defines persuasive communication as any message that is intended to shape, reinforce or change the responses of another or others. Persuasion includes "any effort to modify an individual's evaluation of people, objects or issues by the presentation of a message" (Petty \& Cacioppo, 1987, p. 25). Persuasive communication emphasizes the notion of change, be it change of attitude, behaviour, habits, emotions or beliefs about an issue. Hence any message that is intended to shape, reinforce or change the responses of another, or others, will be defined as persuasive communication (Stiff, 1994, p. 10). 
Several strands of research from different disciplines such as behavioural science, psychology and political science exist in message effect studies. The message effect research of the 1960s attempted to define the characteristics of persuasive messages. In his book Persuasive Communication, James Stiff describes some of the prominent strands in message effect studies:

Rational persuasion: "Persuasive messages that contain rational arguments based on the assumption that people have an implicit understanding of formal rules of logic, and that they apply these rules when making judgements about a source's recommendation" (Stiff, 1994, p. 108). Emphasis of communication is placed on the quality of evidence that is offered to support the conclusion. Rational persuasion emphasizes the importance of supporting information. However, the persuasiveness of the message is dependent on the motivation and ability of the recipient to process the message contained in the message (Petty \& Cacioppo, 1987). Stakeholders who are motivated and fully engaged with the risk issue are more likely to fully scrutinize the message than those who are less engaged. Different stakeholders engage differently in risk issues and hence the importance of adapting the message to the degree of engagement. The degree of stakeholder engagement and their ability to interpret the message is a determinant factor in the understanding of the message and the attitude to change. As such, rational persuasion techniques require that the targeted stakeholders make an active effort in receiving and processing the risk message.

Emotional persuasive appeal: In many persuasive contexts, the message recipients are unable or unmotivated to effectively process rational appeals, and hence under these circumstances persuaders often turn to emotional persuasive appeals (Stiff, 1994). Emotional appeals tap into the subconscious as opposed to the conscious mind. This approach uses manipulation of the emotions to influence the message recipients. This approach is used in different fields including marketing and advertising, where communicators target the subconscious mind through eye-catching adverts. Fear appeals have been used in prevention and safety campaigns, such as Don't Drink and Drive campaigns, the use of seat belts, cigarette smoking and HIV/Aids. In these campaigns, fear-arousing messages, often accompanied by gruesome images, have been used to motivate the target groups to change their behaviour or attitude.

A technical view of risk communications sees communication as a oneway expert-to-lay public information flow, based on the premise that the 
public needs accurate information and scientific expertise (Gutteling \& Wiegman, 1996). In this view the stakeholders' failure to agree with this view is often attributed to a misunderstanding, which should be informed or persuaded 'away' (Gutteling \& Wiegman, 1996). The involvement element has several dimensions, including the intention to persuade individuals and groups and thereby change their perception of the risk. Social and cultural factors determine the processing of risk information and the formation of risk perceptions (Infanti et al., 2013).

\section{Dialogue with Stakeholders}

One of the biggest challenges facing risk communicators is to motivate, persuade or influence stakeholders on matters of risks. As noted in Gutteling and Wiegman (1996), to some risk communication researchers, especially those who hold an implicit technical view of risk communication, there is no problem in trying to reach agreement between the source and the receiver by applying persuasive tools. Other researchers, however, argue that using persuasion communication strategies is not acceptable and contradicts the goals of fairness. More recently, there has been a shift in the understanding of risk communication from merely a one-way communication flow to an emphasis on a two-way communication process involving sharing of information and promoting dialogue between technical experts and stakeholders. This approach acknowledges the concerns of stakeholders. Properly applied dialogue-based risk communication can help stakeholders and experts to share knowledge and understanding of the risk issue. Dialogue is aimed at ensuring that a diverse range of people share a common understanding of the risk issue with the organizations/ individuals in charge of managing the risk concerned.

Sandman (1989) argues that the principle of involving the public in risk issues, whether it is risk assessment, decision-making, management or communication, is crucial. The aim of dialogue-based risk communication is to bring together diverse stakeholders in risk knowledge creation and sharing. This approach recognizes that certain risks are complex and multidisciplinary and hence need to be addressed through dialogue with, and participation by, diverse stakeholders. Increasing stakeholder participation raises the likelihood of the message being credible. There is a growing realization by risk researchers that for risk communication to be effective, it should have a stakeholder perspective. Dialogue-based perspectives are captured in the definition of risk communication by Lang, Fewtrell, and 
Bartram (2001): "[R]isk communication is any purposeful exchange of information about risks between interested parties." In their 'General Principles of Food Safety Risk Management', the World Health Organization (WHO) and the Food and Agriculture Organization (FAO) hold that "risk management should include clear, interactive communication with consumers and other interested parties in all aspects of the process". In its project to investigate what type of communication would improve the public understanding of flood risk and encourage people to take action, the British Environment Agency (2015) carried out a major public dialogue project on flood risk communication. In its project evaluation it found that "getting people and communities involved in talking about flood risks increases people's understanding of local flood risk and can help them on a journey towards making preparations to protect themselves against flooding" (Environment Agency, 2015).

\section{The Risk Message}

Risk communication should be understood as a process that combines different attributes of communication flow, depending on the nature of the risk communication, the technical nature of the information concerned and the stakeholders' ability to engage with the messages. Understanding risk communication as a two-way process envisages that message receivers are active in the communication process (through interpreting and responding). It recognizes the stakeholders' divergent values, beliefs and needs. This perspective addresses "the exchange of information, knowledge and attitudes between decision-makers, experts, stakeholders, and the affected public" (Höppner, Buchecker, \& Bründl, 2010, p. 5).

How should a risk message be communicated? The formulation of risk messages depends on the senders' intentions, be it persuasion or a desire to generate dialogue. The stakeholders, the risk information (message), the channels and the customizing of risk information to the audiences' needs are necessary for more adequate risk communication (Gutteling \& Wiegman, 1996). Blanchard-Boehm (1998) proposes a model that presupposes that the process of risk communication is one whereby individuals (1) hear a warning message; (2) understand its content; (3) internalize or believe the salience of its message; (4) confirm their interpretation with others and (5) act or respond to its message to save their life and property. Morgan and Lave (1990) argue that risk messages must be understood by the recipients, and their impacts and effectiveness must be understood by 
the communicator. A persuasive message is more likely to be effective if the communicator is credible, trusted (depends on qualification and identification), and knowledgeable (expertise). Atwood and Major (1998) argue that individuals who have experienced predictions of disasters that do not materialize will discount the validity of subsequent disaster warnings. The trustworthiness of the sender of a risk message, that is, using trusted sources of information, will enhance the public's compliance with risk messages. Important components of trust include openness, honesty, responsiveness, accuracy, fairness and concern. In addition, the risk message should be tailored to intended audiences, taking into consideration their linguistic skills. The readability of the risk messages should match the target audience's comprehension levels. The choice of message delivery modes should be informed by the target audience's communication habits.

\section{Risk Information Vacuum}

Risk communication has changed dramatically over the last few decades. As Nielson, Kleffner, and Lee (2005) noted that the quantity of information, the quality of information and the parties involved in communication have changed. There have also been changes in the nature of relationships between the senders and intended recipients of a risk message. There is an ever-growing need for organizations to give timely information to their stakeholders. If risk information does not reach its intended recipients in time, a 'risk information vacuum' can emerge. A risk information vacuum arises when "those who are conducting the evolving scientific research and assessments for high-profile risks make no special effort to communicate the results being obtained regularly and effectively to the public" (Powell \& Leiss, 1997).

Risk information vacuum is the result of that failure to implement good risk communication practices. Failures in risk communication lead to rumours and the spread of fear. In the era of fast communications, especially social media, such a risk communication vacuum can quickly be filled by other sources. If the organization is slow in communicating risks, some segments of the stakeholders or interest groups can fill the gap and strengthen their position regarding the risk issues. For example, where environment risks are concerned, environment groups are known to be quick with their information and perspectives. 
The risk information vacuum is a manifestation of a gap between experts and their audiences. From a stakeholder perspective, a risk information vacuum can develop between the risk managers and some of the internal stakeholders (employees, associations) due to the language used to explain the risk. It can also develop between the organizations and some of their diverse external stakeholders. Through its stakeholder analysis and prioritization, the organization can overlook the risk information needs of particular stakeholder groups. It can also overlook the communication competences of the intended stakeholders, by, for example, using scientific language or a communication channel that is not easily accessible to intended recipients.

Effective risk communication can fill this vacuum and translate the language of experts into something stakeholders can more readily understand (Nielson et al., 2005). Powell and Leiss (1997) define a good risk communication practice as communication that seeks to reconcile the language of expert risk assessment and public risk perception, by, for example:

- Translating the scientific findings and probabilistic risk assessment into understandable terms

- Explaining the uncertainty ranges, knowledge gaps

- Addressing the issue of building credibility and trust

- Understanding the public's perspectives on the risk issue

- Acknowledging that questions arising from the public are often quite different from those posed by the experts

- Analysing the conditions needed for allowing the public to acquire needed information, skills and participatory opportunities.(Powell \& Leiss, 1997, p. 30)

Success in risk communication is achieved when an organization has succeeded in communicating risk information to intended stakeholders, thereby earning stakeholder trust, and most importantly avoiding the development of a risk information vacuum. Effective risk communication also involves the ability of an organization to persuade segments of stakeholders. Powell and Leiss (1997) note that statements about risks by various parties are treated as "messages" intended to persuade others to believe or do so something. This perspective is linked to persuasive communication, and risk situations ought to be regarded as acts of persuasive communication, that is, as messages intended to persuade a listener. 


\section{Risk Communication in Crisis Situations}

Crisis situations are often characterized by elements of uncertainty and hence create new risks for organizations involved. Uncertainty surrounding the crisis circumstances poses a number of risks, and significantly intensifies risk variables anchored around the probability of the event causing harm and the consequence of that harm (i.e. to life, property, finance or reputation). The crisis necessitates identification of possible risks (including all types of threats and stakeholders associated with the crisis). After identifying and analysing the risk issue, the organization has to decide how it intends to frame the issue. Framing is the way information is presented. To frame "is to select some aspects of perceived reality and make them more salient in the communication text, in such a way as to promote a particular problem definition, causal interpretation, moral evaluation and/ or treatment recommendation" (Entman, 1993, p. 52). Frames define and interpret problems and their causes, and suggest remedies. Following Entman's postulations, risk communicators (including the media) make conscious or unconscious framing judgements in deciding what to say.

\section{Multiple Stakeholders in Public Health Response}

Health crises that threaten public health fall mainly into the rubric of risk communication, which is aimed primarily at preventing the spread of the disease or virus. The goal is to provide information about the possibilities of exposure, and how to avoid or minimize that risk. The main aim of health risk communication is to convey health information to stakeholders in ways that encourage behavioural changes (Abraham, 2009). So when health pandemics occur, stakeholder communications focus on preventive care. Public health challenges, such as the outbreak of infectious disease epidemics and pandemics, present the risk of transmission. Epidemics such as Ebola, H5Nl avian flu, Severe Acute Respiratory Syndrome (SARS), swine flu and Zika easily cross national boundaries and make news headlines around the world. As the people around the world worry about risk exposure, different media and social media outlets churn out breaking news, warnings and alerts citing sources from different 'experts' and stakeholders. Increasing globalization means that most disease outbreaks have international dimensions.

Health crises have multiple stakeholders and hence voices. Health risks and crises represent highly complex stakeholder dynamics occupying different levels within the national and international health chain system. 
Stakeholders in a health crisis play different roles in relation to others and each has a different viewpoint on the care system, hence different information needs. These stakeholders include policymakers, that is, those who establish the framework with which health services are delivered. This can be ministries of health, agencies or any other jurisdictional entity with responsibility for health prevention and care, within and across national boundaries. The other key stakeholders are service providers, that is, those who operationalize preventive care and care delivery services. Stakeholders such as industry providers include producers (e.g. medical supplies and pharmaceuticals), purchasers and providers. The other group of stakeholders consists of the general public and the patients.

All stakeholders involved in the reduction of risk, for example organizations charged with public health, need a way to communicate with their own stakeholders about current and developing risks. Lemal and Merrick (2013) define health risk communication as "a planned or unplanned communication to the public about the nature, impact and management of a wide array of health threats, such as cancer, HIV/AIDS or influenza". It refers to an exchange of information about the health risks caused by environmental, industrial or agricultural processes, policies or products among individuals, groups and institutions (Glik, 2007). Covello et al. (1987) define health risk communication as "any purposeful exchange of scientific information between interested parties regarding health or environmental risks" or "the act of conveying or transmitting information between interested parties about levels of health or environmental risks" (Covello et al., 1987, p. 112). These definitions incorporate a broader understanding of different stakeholders involved in public health response-be it organizations, institutions or the general public. Including all relevant stakeholders in the processes is a critical factor in risk communication.

\section{Outbreak Communication}

Outbreak communication is the communication that goes out to different stakeholders as soon as a health risk is known. There are often many competing voices in the outbreak phase. Abraham (2009) argues that in such a situation, communication strategists need to strive towards two goals:

- Visibility - the ability to get the message across clearly and prominently to the public and not be drowned by competing voices.

- Legitimacy-ensuring that information is seen as legitimate and authoritative. 
Abraham further notes that if messages are drowned out, distorted or ignored by competing social voices, then outbreak communication will not achieve its public health goal of helping prevent and control outbreaks (Abraham, 2009). Visibility can be achieved through choosing the best channel of communication and the right spokesperson. The WHO has provided guidelines on outbreak communication. The guidelines consist of five principles to guide communication during outbreaks:

- Building trust

- Announcing early

- Being transparent

- Respecting public concerns

- Planning in advance

It should be noted that trust cannot be created during the crisis, it is something that public health organizations should cultivate before the crisis. However, trust alone is not enough. There are other socio-political factors to be considered. As Abraham (2009) argues, "as experiences of SARS and HINl outbreaks have shown, outbreak control and outbreak communication is rarely a pure, clean process of winning public trust and transmitting information objectively and openly" but more often a messy business requiring political decisions with winners and losers (p. 604). He argues that decisions and communications during outbreaks have a political component. Opposing political voices often criticize decisions by public health authorities, using the crisis to score some points. Hence successful communication requires an understanding of the broader political, social and cultural environment in which communication occurs.

Taking into consideration the social and psychological dimensions of health epidemics, Strong (1990) argues that disease epidemics are accompanied by three kinds of psychosocial epidemics: epidemics of fear, of explanation and of action. He argues that the three phases can occur simultaneously:

Any society gripped by a florid form of epidemic psychology may, therefore, simultaneously experience waves of individual and collective panic, outbursts of interpretation as to why the disease occurred, rashes of moral controversy, and plagues of competing control strategies, aimed at either containing the disease itself, or else at controlling the further epidemics of fear and social dissolution. (Strong, 1990) 
The epidemic of fear is characterized by widespread suspicions of people or environments that might be potentially infectious.

\section{The Ebola Crisis}

The West African Ebola virus epidemic (2013-2016) was recorded first in Guinea in December 2013 before spreading widely to the neighbouring countries of Sierra Leone and Liberia, with smaller outbreaks in Nigeria, Mali and Senegal, and with imported cases registered in the USA, Spain, the UK and Norway. The risk of transmission elsewhere in the world and the perceived consequences for those affected attracted a lot of attention from different actors, both governmental and non-governmental organizations, at national, regional and global levels-all with different interests in the outbreak. A number of voices strove to be heard on both the oral and modern communication platforms. Communication platforms were quickly flooded with messages, and amidst this maze, turmoil ensued. Communication was hence identified as being one of the major issues of concern during the Ebola outbreak. An information crisis prevailed as stakeholder groups, in particular those affected by the crisis, grappled with sources of information to trust, amidst a sea of misleading or misinformed material. Unclear, inconsistent and conflicting messages emanating from many authorities (i.e. government, traditional leaders and religious leaders), some of which were mistrusted, compounded the situation. As such, early messages concerning Ebola were met with both fear and denial by many communities.

The Assessment Capacities Project (ACAPS) report observed in the case of Sierra Leone that "as the outbreak spread, it was important to find appropriate ways to tell people how to minimize the risk of catching the disease and what to do if it affected them and their families" (ACAPS, 2015). It also noted that the early messages designed to change behaviour were counterproductive as they failed to take into account cultural practices and beliefs. The message to the public may simply be public information that is required for people to protect themselves, for example, from the disease and reduce the risk of transmission, but then in a context characterized by many voices (with different cultural backgrounds) and many communication channels (both oral and modern), the messages reaching the public were sometimes incomprehensible and contradictory. Cultural factors also had a bearing on whether those messages were acted upon. The chaos in the 
communication of risk in West Africa can be attributed to the failure to integrate local knowledge and voices into the formulation and communication of risk knowledge.

The chaos in communication was not only identified in West Africathe USA experienced a similar situation when the first case of Ebola was reported. The Liberian national Thomas Eric Duncan travelled to Dallas, Texas, from Liberia and died two weeks later. Communication chaos followed. Two nurses became infected while caring for him. In an article called "Ebola Crisis-Communication Chaos We Can Avoid", Ratzan and Moritsugu (2014) note how "this pattern of communication chaos tests our ability to appropriately reach and inform citizens with understandable, reliable, and actionable news (information) they can use" (p. 1213). They argue that the communication chaos surrounding the Ebola crisis in the USA shows that "communication that works for policymakers and medical personnel, and is understood by them, may be very different from communication that works for the public. This is where we need to understand that one message does not fit all" (p. 1214). As was the case in West Africa, messages that worked for one group did not work for others.

It becomes more crucial for crisis managers and other decision-makers to have knowledge about those stakeholders who are affected by the decisions and actions taken, and their influence and power. In West Africa, attempts were made to empower affected communities and use local voices in the information and behavioural change campaigns. Community mobilization helps to bridge trust and reliability barriers. Social mobilization efforts enhance two-way forms of communication limiting top-down communication, which lacks grass-roots support.

The Ebola case highlights the importance of understanding stakeholder communication patterns in the local context, that is, forms of communication (both traditional and modern), patterns of access to information, and perceptions on communication messages and messengers. The voices from below, that is, those of local chiefs, village heads, religious leaders, opinion leaders, influencers and women's and youth leaders, are equally important for effective risk communication.

\section{The Egg Crisis}

In the summer of 2017, eggs tainted with the pesticide Fipronil, discovered first in Belgium, then the Netherlands and later Germany, ignited a scare across Europe. Exposure to large quantities of Fipronil can cause 
damage to kidneys, liver and lymph glands. As such, the contaminated eggs posed a public health risk to consumers and accordingly millions of eggs were recalled from shops and warehouses in the UK, the Netherlands, Germany, Belgium and other European countries. The recall extended to other products, such as salads and sandwiches, where contaminated eggs were used as ingredients. As a precautionary measure, some supermarket chains withdrew the eggs from their shelves.

The scope of the egg crisis illustrates the complexity of food chains and the ease with which risk foods can affect consumers in different parts of the world. Communicating with stakeholders during the outbreak of foodborne diseases, that is, those threats posed by contaminated food, pathogenic bacteria and viruses, presents a series of challenges. These include the consistency of the messages, their persuasiveness and the stakeholder characteristics. Food chain security is a highly complex issue often involving a multitude of stakeholders. The whole national economic sector of food production and distribution is vulnerable to a local accident (Brunet \& Houbaert, 2007). The stakeholders involved are not monolithic blocks but very dynamic entities. In their study of the Belgian fowl pest crisis, Brunet and Houbaert (2007) note how during the fowl pest crisis, a new group of influential stakeholders emerged: stakeholders who were not used to communicating with public authorities responsible for the food chain. The authorities, for their part, were not quickly able to establish a valid understanding of these stakeholders during the crisis. "Unless the stakeholders likely to be implicated in any crisis are explicitly recognized, therefore, it is likely that some of those who need to be protected from the adverse consequences of the event will be neglected or poorly served" (Brunet \& Houbaert, 2007, p. 647). In light of the crossborder dimensions of food safety, there have been efforts at international level to coordinate food risk messages. For example, the International Food Safety Authorities Network (INFOSAN) connects national authorities from around the world. Its objective is to prevent the international spread of foodborne disease by promoting the rapid exchange of information during food safety events, sharing information on food safety issues and promoting collaboration between countries.

\section{From One-Way to Two-Way Communication Flow}

Early health risk communication models were based on a one-way flow of risk messages to the public. The dominant focus in these one-way models was 
on the experts (government and health institutions) disseminating messages about health threats to the public, conceived as being passive. This understanding was underpinned by the 'effect studies' tradition, such as hypodermic needle theory (also known as the magic bullet theory), which suggested that the mass media could influence the masses directly by 'shooting' or 'injecting' them with appropriate messages designed to trigger a desired response. These theories suggest a powerful and direct flow from the sender to the receiver, in our case from health authorities to the public.

There was, however, a paradigm shift in the 1990s that saw a change from top-down communication about health threats. New approaches to risk communication advocate a more inclusive two-way process of communication, placing more emphasis on the interaction between the communicator and the audience. The new perspectives focus on risk communication as a dialogue or as a dynamic exchange of information. The interactive perspective on health risk communication moves beyond the old view of a passive receiver and instead focuses on how health risk messages can elicit different responses depending on (a) who communicates them, (b) how they are communicated and (c) how the public actively processes the information (Lemal \& Merrick, 2013). Researchers in health risk communication have cited the following principles as being central for increasing the effectiveness of risk communication.

1. Engage in a dialogue with the audience

2. Explain risk information

3. Simplify and personalize risk messages

4. Recognize the validity of public concerns (Williams, 2004)

Williams places more emphasis on dialogue with the audience. Dialogue can only be achieved through conversational exchange within a space of presumed equality.

\section{The Media and the Framing of Health Risk}

During public health crises, the media constitute a prime arena for making sense of the risk. They play a central role in informing the public about the risks and hence they constitute key sites responsible for 'defining risks' (Beck, 1986) and in the 'construction of' and 'communication about' risk (Kitzinger, 1999). There has been a lot of research on the 
media's role in defining and presenting risks. Beck (1986) emphasizes the role of the mass media "in the social construction, social contestation, and further, social criticism, or social challenge to, risks and the deficiencies of institutionalized responses to these" (Cottle, 1998, p. 9). Other researchers have focused on how media construct and represent risks (Bakir, 2010). Bakir's (2010) research examines the different routes of media-risk research, which include the media's role in providing risk knowledge to inform citizens, modulating public acceptability of different risks and motivating the public to take responsibility for, and action regarding, risks.

The media play a crucial role in the framing contest that ensues in the wake of a crisis. In their coverage and representation, the media can also minimize or maximize the scope and significance of the risk. The media's framing of the health risk influences the stakeholders' perception of the risk. In their study of the coverage of the 2009 swine flu pandemic by major US newspapers, Yu, Frohlich, Fougner, and Ren (2013) argue that generally audiences assess a health risk and make judgements about their daily-life behaviours based on the perceived severity of the disease presented by the media. They note how in the case of the 2009 swine flu pandemic, fear of the HINl flu swept around the world faster than the virus itself. The frame of fear and anxiety is not new in media coverage of health risk. Blakely's research shows how the New York Times framed the 1918, 1957 and 1968 flu pandemics through the lens of anxiety and fear (quoted in Yu et al., 2013).

The audience also learn preventive methods from the media. The media can contribute to the public assessment of a health risk and provide general knowledge about basic preventive methods (Yu et al., 2013). As noted by Chen and Murphy (2013), public health practitioners and researchers are paying increased attention to the potential role that the mass media can play in facilitating public understanding of emerging infectious diseases and in motivating public compliance with precautionary measures recommended by public health agencies.

However, the challenge is that media framing of risks tends to be biased towards sensational and dramatic stories. Scientists and policymakers often complain that the media misrepresent risk statistics and distort the facts, by, for example, giving a platform to scaremongers and mavericks and seeking out "doom-laden scenarios" (Kitzinger, 1999). This has been particularly the case in the coverage of health pandemics. The media reporting on health pandemics such as bird flu, SARS and so on bears testimony 
to the increased competition to frame the risks. It is often the negative frame (lives likely to be lost) that reaches the public domain rather than the positive frame (lives likely to be saved). In reporting risk in health, the media do not operate in the same way as (or necessarily reflect the mainstream views of) doctors, scientists, researchers or health officials in presenting information to the public (Greenberg, Sachsman, Sandman, \& Salomone, 1989; Kitzinger, 1999; Rothman \& Lichter, 1987). The media play a significant role in raising risk awareness, engaging the public in debate, investigating alternatives and promoting transparency and inclusive communication policies. Different groups of stakeholders interpret risks differently, and so do the media. There are dangers, therefore, of a risk gap developing between an organization and its stakeholders due to media framing.

The effectiveness of health risk messages is highly dependent on how these messages are constructed or framed (Lemal \& Merrick, 2013). The media play a pivotal role in the communication of risks, by influencing who communicates and what is communicated. They play an important role in communicating health risk information and in shaping the perception of stakeholders. Advances in new media have dramatically changed the role of risk communication, impacting on how organizations interact with their internal and external stakeholders. The implications of these changes to risk communication is that "the number of people and speed of diffusion has created unparalleled challenges as our social media obliterates hierarchy and perhaps creates a 'flat' or 'nobody in charge' world" (Ratzan, 2014, p. 1327). Risk information from different stakeholder perspectives and from the organization can easily be disseminated through new media.

\section{Post-Crisis Risk Management}

Risks do not disappear after the crisis as old risk areas can persist long after the original crisis event is over. There will always be some risk factors in every organization. As such, risk management after crisis integrates most of the pre-crisis risk management processes cited earlier. Communicating risks to stakeholders is a continuous process, in which the organization works systematically in identifying, assessing, prioritizing, managing and communicating both present and emerging risks. Involving stakeholders in the organization's overall risk communication plan helps build trust and confidence between the organization and its stakeholders. 


\section{CONCLUSION}

Communicating risk requires a profound understanding of the risk stakeholders. For risk communication to succeed, it is imperative that the communicator understands the stakeholders and how they perceive the potential risk. Identifying, assessing and segmenting the stakeholders, understanding their concerns and perceptions, would enable the communicator to design better risk communication strategies. It would enable the communicator to design better risk messages, customize messages for specific target groups and ensure that stakeholders receive relevant messages. It is equally important for the communicator that the stakeholders want to be involved. One-way forms of communication, in which the stakeholders are mainly seen as receivers of information from experts, are no longer considered acceptable. Risk communication is now a two-way form of communication, with emphasis on interaction and dialogue between an organization and its stakeholders. Hence communications that enhance interactions, elicit responses and generate dialogue are preferable. Openness (e.g. involving representatives from affected stakeholders) enables an organization to get input from outside the organization, thereby improving the quality of interactions. A dynamic, flexible risk communication approach that involves stakeholders at every possible stage can enhance the effectiveness and credibility of risk communication throughout the crisis management cycle.

\section{REFERENCES}

Abraham, T. (2009). Risk and Outbreak Communication: Lessons from Alternative Paradigms. Bulletin, pp. 604-607. Retrieved from https://www. scielosp.org/pdf/bwho/2009.v87n8/604-607; https://doi.org/10.2471/ BLT.08.058149/.

ACAPS. (2015). Ebola Outbreak, Sierra Leone: Communication: Challenges and Good Practices. Retrieved from https://www.acaps.org/sites/acaps/files/ products/files/v_sierra_leone_communication_challenges_and_good_practice_dec_2015_2-ilovepdf-compressed_ul.pdf

Atwood, E. L., \& Major, A. M. (1998). Exploring the 'Cry Wolf' Hypothesis. International Journal of Mass Emergencies and Disasters, 16(3), 279-302.

Bakir, V. (2010). Media and Risk: Old and New Research Directions. Journal of Risk Research, 13(1), 5-18. https://doi.org/10.1080/13669870903135953

Beck, U. (1986). Risk Society: Towards a New Modernity (M. Ritter, Trans.). London: Sage Publications. 
Beck, U. (2009). World of Risks (C. Cronin, Trans.). Cambridge: Polity Press. Blanchard-Boehm, D. R. (1998). Understanding Public Response to Increased Risk from Natural Hazards: Application of the Hazards Risk Communication Framework. International Journal of Mass Emergencies and Disasters, 16(3), 247-278.

Brunet, S., \& Houbaert, P. (2007). Involving Stakeholders: The Belgian Fowl Pest Crisis. Journal of Risk Research, 10(5), 643-660. https://doi.org/ $10.1080 / 13669870701281454$

Chen, N.-T. N., \& Murphy, S. T. (2013). Examining the Role of Media Coverage and Trust in Public Health Agencies in HINl Influenza Prevention. In M. Lemal \& J. Merrick (Eds.), Health Risk Communication. New York, NY: Nova Science Publishers, Inc.

Coombs, W. T. (2015). Ongoing Crisis Communication. Planning, Managing, and Responding (4th ed.). Los Angeles: Sage.

Cottle, S. (1998). Ulrich Beck, 'Risk Society' and the Media: A Catastrophic View? European Journal of Communication, 13(1), 5-32. https://doi. org/10.1177/0267323198013001001

Covello, V. T., Winterfeldt, D., \& Slovic, P. (Eds.). (1987). Uncertainty in Risk Assessment, Risk Management, and Decision Making. New York, NY: Plenum Press.

Entman, R. M. (1993). Framing: Toward Clarification of a Fractured Paradigm. Journal of Communication, 43(4), 51-58.

Environment Agency. (2015). Public Dialogues on Flood Risk Communication (SC120010/R1). Retrieved from www.gov.uk/government/organisations/ environmentagency

Glik, D. C. (2007). Risk Communication for Public Health Emergencies. Annual Review of Public Health, 28(1), 33-54. https://doi.org/10.1146/annurev. publhealth.28.021406.144123

Greenberg, M. R., Sachsman, D. B., Sandman, P. M., \& Salomone, K. L. (1989). Risk, Drama and Geography in Coverage of Environmental Risk by Network TV. Journalism \& Mass Communication Quarterly, 66(2), 267-276. https:// doi.org/10.1177/107769908906600201

Gutteling, J. M., \& Wiegman, O. (1996). Exploring Risk Communication. Netherlands: Springer.

Höppner, C., Buchecker, M., \& Bründl, M. (2010). Risk Communication and Natural Hazards (CapHaz-Net WP5 Report). Birmensdorf, Switzerland. Retrieved from http://caphaznet.org/outcomes-results/CapHaz-Net_WP5_ Risk-Communication.pdf

Infanti, J., Sixsmith, J., Barry, M., Nunez-Codoba, J., Oroviogoicoechea-Ortega, C., \& Guillen-Grima, F. (2013). A Literature Review on Effective Risk Communication for the Prevention and Control of Communicable Diseases in Europe. Retrieved from https://ecdc.europa.eu/sites/portal/files/media/ 
en/publications/Publications/risk-communication-literary-review-jan-2013. pdf; https://doi.org/10.2900/64747.

Institute of Medicine. (1997). Risk Communication and Vaccination: Worksop Summary (9780309573627). Washington, DC. Retrieved from http://site. ebrary.com/lib/hedmark/docDetail.action?docID=10057039

Jardine, C. (2008). Stakeholder Participation in Risk Management Decision Making. In E. L. Melnick \& B. S. Everitt (Eds.), Encyclopedia of Quantitative Risk Analysis and Assessment. https://doi.org/10.1002/9780470061596.risk0012.

Kallman, J. W., \& Maric, R. V. (2004). A Refined Risk Management Paradigm. Risk Management, 6(3), 57-68.

Kitzinger, J. (1999). Researching Risk and the Media. Health, Risk er Society, 1(1), 55-69.

Lang, S., Fewtrell, L., \& Bartram, J. (2001). Risk Communication. In W. H. O. (WHO) (Ed.), Water Quality. Guidelines, Standards and Health: Assessment of Risk and Risk Management for Water-Related Infectious Disease. London: IWA Publishing.

Lemal, M., \& Merrick, J. (2013). Health Risk Communication. New York, NY: Nova Science Publishers, Inc.

Miller, G. R. (1980). On Being Persuaded: Some Basic Distinctions. In G. R. Miller \& M. E. Roloff (Eds.), Persuasion: New Directions in Theory and Research. New York, NY: Harper \& Row.

Morgan, M. G., \& Lave, L. (1990). Ethical Considerations in Risk Communication. Risk Analysis, 10, 355-358.

Nielson, N. L., Kleffner, A. E., \& Lee, R. B. (2005). The Evolution of the Role of Risk Communication in Effective Risk Management. Risk Management and Insurance Review, 8(2), 279-289.

Petty, R. E., \& Cacioppo, J. T. (1987). Communication and Persuasion: Central and Peripheral Routes to Attitude Change. New York, NY: Springer-Verlag.

Plough, A., \& Krimsky, S. (1987). The Emergence of Risk Communication Studies: Social and Political Context. Science, Technology \& Human Values, $12(3 \& 4), 4-10$.

Powell, D. A., \& Leiss, W. (1997). Mad Cows and Mother's Milk: The Perils of Poor Risk Communication. Montreal, QC: McGill-Queen's University Press.

Ratzan, S. C. (2014). Twenty Years Later: Ebola, AIDS, BSE and NCDs-What Have We Learned? Journal of Health Communication, 19(12), 1327-1329. https://doi.org/10.1080/10810730.2014.989098

Ratzan, S. C., \& Moritsugu, K. P. (2014). Ebola Crisis-Communication Chaos We Can Avoid. Journal of Health Communication, 19(11), 1213-1215. https://doi.org/10.1080/10810730.2014.977680

Rothman, S., \& Lichter, S. R. (1987). Elite Ideology and Risk Perception in Nuclear Energy Policy. The American Political Science Review, 81(2), 383-404. https://doi.org/10.2307/1961958 
Sandman, P. M. (1989). Hazard Versus Outrage in the Public Perception of Risk. In V. T. Covello, D. B. McCallum, \& M. T. Pavlova (Eds.), Effective Risk Communication: The Role and Responsibility of Government and Nongovernment Organizations (pp. 45-49). Boston, MA: Springer US.

Stiff, J. B. (1994). Persuasive Communication. New York, NY: The Guilford Press. Strong, P. (1990). Epidemic Psychology: A Model. Sociology of Health and Illness, 12(3), 249-259.

Williams, P. R. D. (2004). Health Risk Communication Using Comparative Risk Analyses. Journal of Exposure Analysis and Environmental Epidemiology, 14, 498-515.

Yu, N., Frohlich, D. O., Fougner, J., \& Ren, L. (2013). Reporting the Risks of the 2009 Swine Flu Pandemic: Coverage in Major U.S. Newspapers. In M. Lemal \& J. Merrick (Eds.), Health Risk Communication. New York, NY: Nova Science Publishers, Inc. 